Check for updates

Cite this: RSC Adv., 2018, 8, 35690

\title{
Simulation of nitrogen transformation in pressurized oxy-fuel combustion of pulverized coal
}

\author{
Xiaorui Liang, Qinhui Wang, (D)* Zhongyang Luo, Heng Zhang, Kaikun Li, Yi Feng, \\ Abdul Rahim Shaikh and Jianmeng Cen
}

Chemical kinetic modeling was applied to simulate $N$ transformation in the pressurized oxy-fuel combustion process of pulverized coal. Modeling accuracy was validated by experimental data at different operation pressures. The key reaction paths from fuel- $\mathrm{N}$ to different $\mathrm{N}$ products were revealed by analyzing the rate of production. NO formation was synergistically affected by six elementary reactions, in which $\mathrm{NCO}$ and other intermediate species were involved. The reactions among $\mathrm{N}, \mathrm{NH}$, $\mathrm{NH}_{2}$, and $\mathrm{NO}$ were the key paths of $\mathrm{N}_{2}$ formation. After pressurizing the combustion system, $\mathrm{NO}$ and $\mathrm{N}_{2}$ contents decreased and increased, respectively. High operation pressure inhibited the diffusion of NO from the internal to the external part of char. This condition prolonged the residence time of NO inside the char, triggered a typical heterogeneous reaction between gaseous NO and unburned char, and reduced the conversion from fuel- $\mathrm{N}$ to $\mathrm{NO}$. Moreover, modeling was performed to predict $\mathrm{NO}_{x}$ emission in pressurized oxy-fuel combustion as a function of various operating parameters, including temperature and excess air and recycling ratios. This study may provide guidance for reducing $\mathrm{NO}_{x}$ emissions and improving combustion efficiency in oxy-fuel combustion, and it can serve as a reference for industrial applications that involve pulverized coal combustion.

Received 12th September 2018
Accepted 14th October 2018

DOI: $10.1039 / \mathrm{c} 8 \mathrm{ra0} 07594 \mathrm{~h}$

rsc.li/rsc-advances combustion process has lower temperatures and higher char concentrations than air-fired combustion. ${ }^{\mathbf{1 0 - 1 3}}$

The formation mechanism of $\mathrm{NO}_{x}$ during oxy-fuel combustion has been investigated mainly under atmospheric pressure conditions, and only a few studies have reported $\mathrm{N}$ transformation under pressurized oxy-fuel combustion. Lasek et al. ${ }^{\mathbf{1 4}}$ set up a pressurized oxy-fuel combustion process and observed reduced NO emission in air-fired and oxy-fuel pressurized combustion. The authors concluded that the positive influence of pressure on NO reduction is the creation of preferential conditions for the NO-char reaction. Lei et al. ${ }^{15}$ investigated the release behavior of $\mathrm{NO}_{x}$ during pressurized oxy-fuel combustion of Datong bituminous coal and discovered that $\mathrm{NO}_{2}$ emission declines at $3 \mathrm{MPa}$ due to the accelerated decomposition rate of $\mathrm{NO}_{2}$ at high combustion temperatures. However, the characterizations applied in these studies limited the demonstrations, and the elementary reactions involving the combustion process were unclear. Therefore, the $\mathrm{N}$ transformation mechanism during pressurized oxy-fuel combustion still requires clarification. Moreover, modeling studies on $\mathrm{NO}_{x}$ emissions in oxy-fuel combustion focused on gaseous fuels. ${ }^{12,16}$ Modeling of pulverized coal relied on computational fluid dynamics codes with simplified schemes of nitrogen transformation and exhibited limited accuracy when compared with experimental results. ${ }^{17}$

In the present study, a chemical engineering model was applied to simulate $\mathrm{NO}_{x}$ formation and consumption during pressurized oxy-fuel combustion. This work aims to predict $\mathrm{NO}_{x}$ 


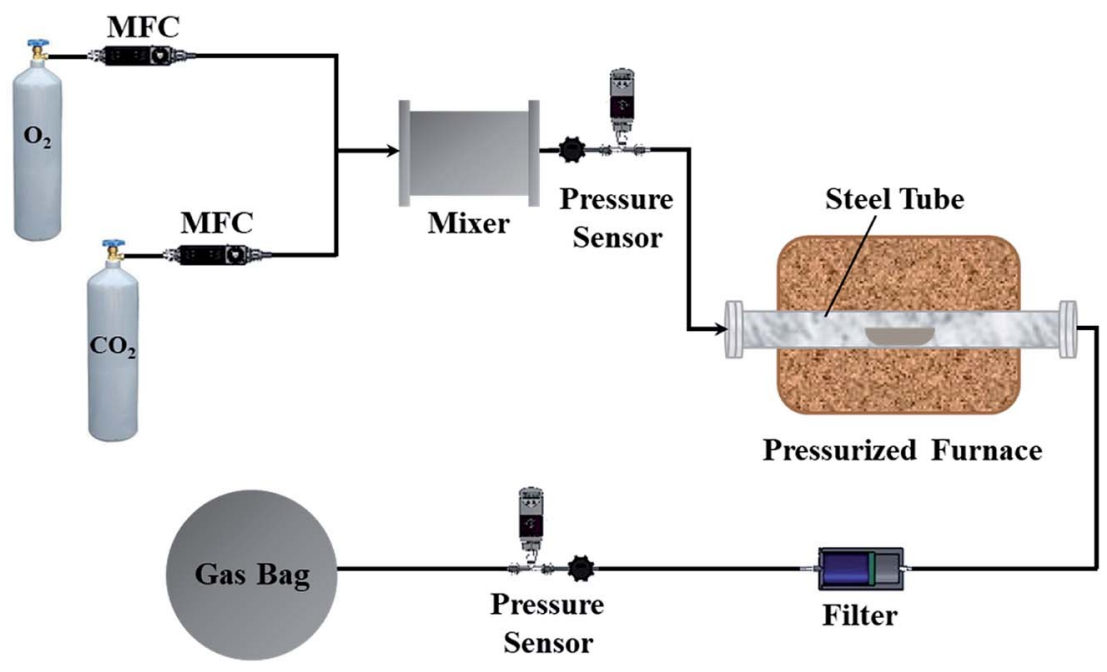

Fig. 1 Schematic of the experimental apparatus.

combustion, the gas bag was transferred and connected to the FTIR instrument. The pipeline that connected the gas bag and FTIR instrument was maintained at $180{ }^{\circ} \mathrm{C}$ to prevent the gaseous species from condensing. The measurement frequency of the FTIR instrument was set to $3 \mathrm{~s}$. The species concentration of each sampling point was measured by the FTIR instrument three times and averaged to ensure high accuracy. Additionally, a gas chromatograph (Agilent 7890A, USA) equipped with a thermal conductivity detector (TCD) was utilized to measure the $\mathrm{N}_{2}$ concentration. Each experiment was conducted three times and averaged to ensure that the relative standard deviations were below $3 \%$.

\section{Results and discussion}

\subsection{Model validation}

Modeling accuracy was validated by comparing the molar fraction of the major combustion products at different operation pressures in the numerical simulation and experimental results. The experiments and modeling were conducted at

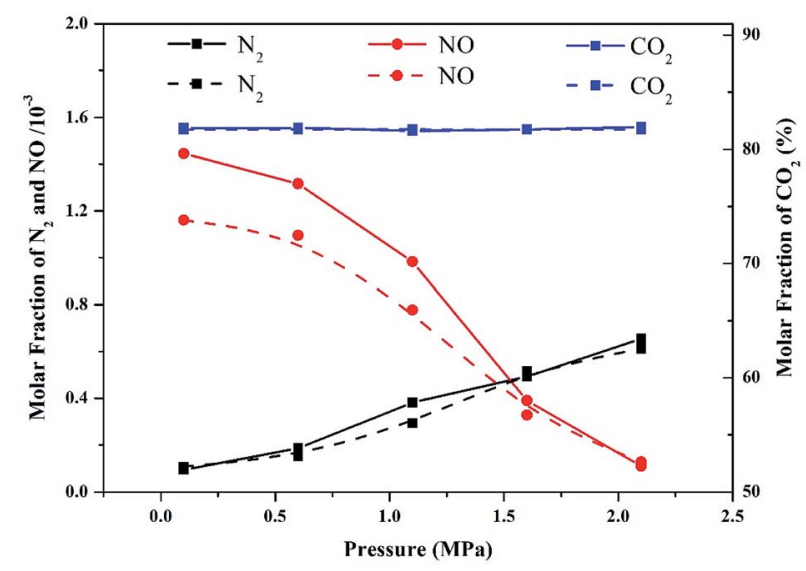

Fig. 2 Comparison of experimental data (solid lines) and modeling results (dashed lines) of major combustion products as a function of operation pressure in pressurized oxy-fuel combustion. a temperature of $900{ }^{\circ} \mathrm{C}$. As shown in Fig. 2, the NO and $\mathrm{N}_{2}$ contents in the experimental data and modeling predictions decreased and increased, respectively, as the operation pressure increased. However, the modeling results of NO content were slightly underestimated compared with those of the experimental data. This result can be ascribed to the temperature variation during the combustion process. Although the temperatures in the modeling and experiment part were set to be similar $\left(900^{\circ} \mathrm{C}\right)$, the actual temperature in the experimental part might have slightly exceeded $900{ }^{\circ} \mathrm{C}$ due to the exothermic reaction of combustion. Therefore, the oxidation of fuel-N into NO accelerated, resulting in high values of NO content in the experimental results. Additionally, the concentration of $\mathrm{CO}_{2}$ emitted from the flue gas was nearly constant in the entire pressure range, implying that the majority of volatiles were completely combusted in pressurized oxy-fuel combustion. As demonstrated in Fig. 2, the simulation results are in good agreement with the experimental data. Therefore, the reaction mechanism and calculation method applied in this work are reasonable and convincing.

\subsection{Nitrogen products and free radicals}

Fuel-N is the only source of final nitrogen products in oxy-fuel combustion. In the current modeling of pulverized coal, HCN was added as fuel-N. The modeling results showed that NO, $\mathrm{NO}_{2}, \mathrm{~N}_{2} \mathrm{O}$, and $\mathrm{N}_{2}$ were the primary $\mathrm{N}$ products. The molar fractions of the four products varied along the homothermal length of the reactor, as illustrated in Fig. 3. The coal sample was rapidly pushed into the center of the steel tube after the reactor was preheated, as indicated in Section 2.3. Thus, the start point of the distance in Fig. 3 is the center of the steel tube.

As displayed in Fig. 3a, the molar fraction of NO increased sharply to $1.16 \times 10^{-3}$ at the initial stage of oxy-fuel combustion then remained almost unchanged until the end of the combustion. The molar fraction of $\mathrm{N}_{2}$ increased to $1.08 \times 10^{-4}$, indicating that $\mathrm{N}_{2}$ was the second most abundant product. Two other conventional $\mathrm{N}$ compounds, namely, $\mathrm{NO}_{2}$ and $\mathrm{N}_{2} \mathrm{O}$, were observed among the products. The molar fractions of $\mathrm{NO}_{2}$ and 

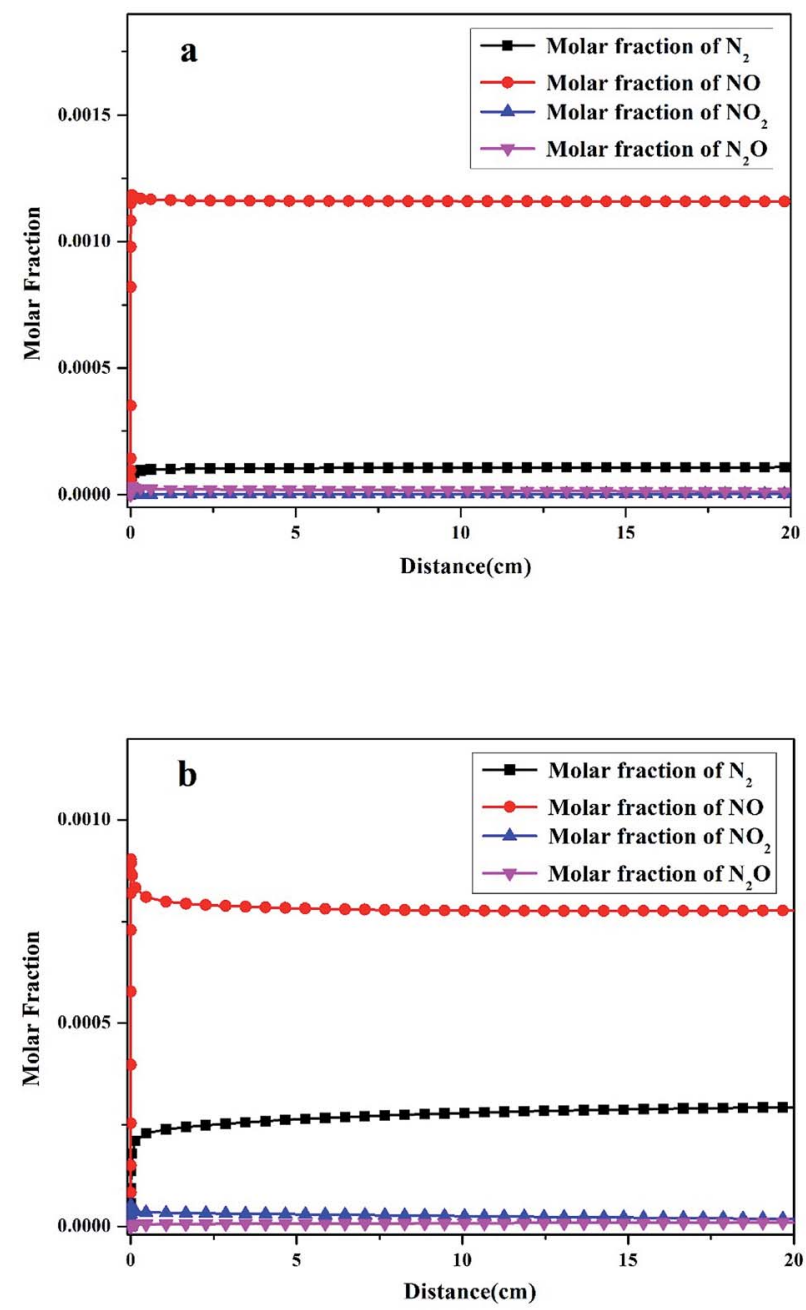

Fig. 3 Molar fraction of main nitrogen products as a function of reactor distance in (a) atmospheric oxy-fuel combustion and (b) pressurized (1.1 MPa) oxy-fuel combustion. The modeling is simulated at a temperature of $900{ }^{\circ} \mathrm{C}$ and excess air ratio of 1.0 .

$\mathrm{N}_{2} \mathrm{O}$ were $3.43 \times 10^{-6}$ and $1.18 \times 10^{-5}$, respectively. After the initial stage of oxy-fuel combustion, the molar fractions of the four $\mathrm{N}$ products remained constant, indicating that the combustion system was stable.

However, the yields of the four $\mathrm{N}$ products differed remarkably after introducing operation pressure (1.1 MPa) into this combustion system. As indicated in Fig. 3b, the molar fraction of NO decreased from $1.16 \times 10^{-3}$ to $7.78 \times 10^{-4}$ during atmospheric and pressurized oxy-fuel combustion. Meanwhile, the molar fraction of $\mathrm{N}_{2}$ increased gradually and stabilized at $2.93 \times 10^{-4}$. Notably, the yield of NO declined by $30 \%$, whereas that of $\mathrm{N}_{2}$ increased by nearly three times compared with atmospheric pressure. The $\mathrm{NO}_{2}$ and $\mathrm{N}_{2} \mathrm{O}$ contents were $1.78 \times$ $10^{-5}$ and $1.33 \times 10^{-5}$, respectively, suggesting that the production of $\mathrm{NO}_{2}$ was promoted and slightly exceeded that of $\mathrm{N}_{2} \mathrm{O}$.

The molar fraction changes of $\mathrm{H}, \mathrm{O}$, and $\mathrm{OH}$ radicals in the combustion process are also shown in Fig. 4. The maximum molar fractions of the three radicals (Fig. 4) are much higher than those of the $\mathrm{N}$ products in atmospheric and pressurized

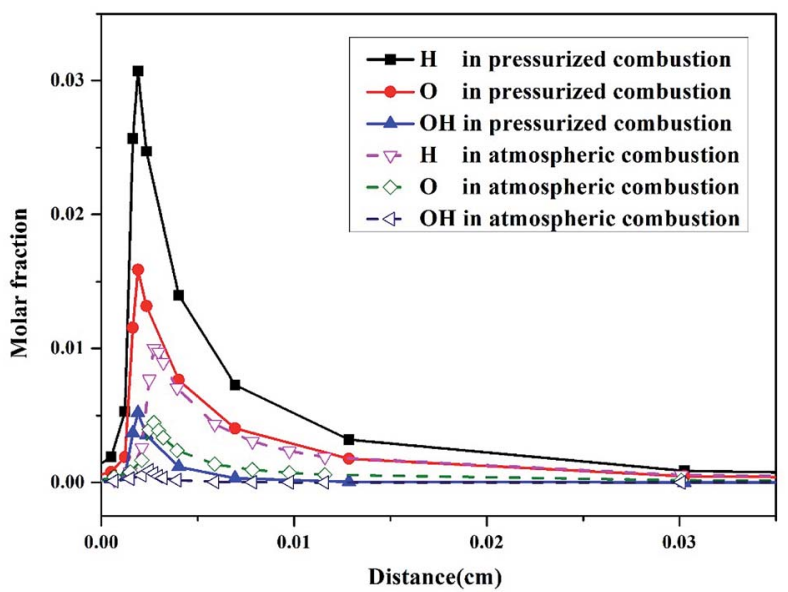

Fig. 4 Molar fraction of $\mathrm{H}, \mathrm{O}$, and $\mathrm{OH}$ radicals as a function of reactor distance in atmospheric oxy-fuel combustion (dashed lines) and pressurized (1.1 $\mathrm{MPa}$ ) oxy-fuel combustion (solid lines). The modeling is simulated at a temperature of $900{ }^{\circ} \mathrm{C}$ and excess air ratio of 1.0 .

oxy-fuel combustion (Fig. 3). This result implies that $\mathrm{H}, \mathrm{O}$, and $\mathrm{OH}$ radicals are vital to the ignition process at the initial stage of combustion. Studies ${ }^{28,29}$ have proven that in the ignition process of fuel combustion, the chain branch reaction R1: $\mathrm{H}+\mathrm{O}_{2} \Leftrightarrow \mathrm{O}+$ $\mathrm{OH}$ (Table 3) plays the leading role in promoting combustion. Additionally, all three radicals' molar fractions in the initial stage of pressurized oxy-fuel combustion were superior to those in atmospheric oxy-fuel combustion. This result indicates that the reaction rate is much faster in pressurized oxy-fuel combustion than in atmospheric oxy-fuel combustion. This result can be explained by classic chemical reaction collision theory. ${ }^{30}$ The quantity of activated molecules in the reaction system increases as the pressure increases, thereby increasing the number of effective collisions and improving the rate of chain branch reaction R1. Furthermore, R1 consumes one $\mathrm{H}$ radical and generates two radicals $(\mathrm{O}$ and $\mathrm{OH})$ simultaneously.

Table 3 Major elementary reactions involving nitrogen transformation

\begin{tabular}{llll}
\hline No. $^{a}$ & $\begin{array}{l}\text { Chemical reaction } \\
\text { equation }\end{array}$ & No. $^{a}$ & $\begin{array}{l}\text { Chemical reaction } \\
\text { equation }\end{array}$ \\
\hline $\mathrm{R} 1$ & $\mathrm{H}+\mathrm{O}_{2} \Leftrightarrow \mathrm{O}+\mathrm{OH}$ & $\mathrm{R} 442$ & $\mathrm{NH}+\mathrm{NO} \Leftrightarrow \mathrm{NNH}+\mathrm{O}$ \\
$\mathrm{R} 351$ & $\mathrm{HNO}+\mathrm{H} \Leftrightarrow \mathrm{NO}+\mathrm{H}_{2}$ & $\mathrm{R} 514$ & $\mathrm{HCN}+\mathrm{M} \Leftrightarrow \mathrm{HNC}+\mathrm{M}$ \\
$\mathrm{R} 361$ & $\mathrm{NO}+\mathrm{HO}_{2} \Leftrightarrow \mathrm{NO}_{2}+\mathrm{OH}$ & $\mathrm{R} 516$ & $\mathrm{HCN}+\mathrm{O} \Leftrightarrow \mathrm{NCO}+\mathrm{H}$ \\
$\mathrm{R} 391$ & $\mathrm{~N}_{2} \mathrm{O}+\mathrm{H} \Leftrightarrow \mathrm{N}_{2}+\mathrm{OH}$ & $\mathrm{R} 521$ & $\mathrm{HCN}+\mathrm{OH} \Leftrightarrow \mathrm{HNCO}+\mathrm{H}$ \\
$\mathrm{R} 417$ & $\mathrm{NH}_{2}+\mathrm{NO} \Leftrightarrow \mathrm{N}_{2}+\mathrm{H}_{2} \mathrm{O}$ & $\mathrm{R} 526$ & $\mathrm{HNC}+\mathrm{O} \Leftrightarrow \mathrm{NH}+\mathrm{CO}$ \\
$\mathrm{R} 418$ & $\mathrm{NH}+\mathrm{NO} \Leftrightarrow \mathrm{NNH}_{2}+\mathrm{OH}$ & $\mathrm{R} 527$ & $\mathrm{HNC}+\mathrm{OH} \Leftrightarrow \mathrm{HNCO}+\mathrm{H}$ \\
$\mathrm{R} 422$ & $\mathrm{NH}+\mathrm{H} \Leftrightarrow \mathrm{N}+\mathrm{H}_{2}$ & $\mathrm{R} 537$ & $\mathrm{CN}+\mathrm{NO} \mathrm{N}_{2}+\mathrm{CO}$ \\
$\mathrm{R} 423$ & $\mathrm{NH}+\mathrm{O} \Leftrightarrow \mathrm{NO}+\mathrm{H}$ & $\mathrm{R} 544$ & $\mathrm{HNCO}+\mathrm{H} \Leftrightarrow \mathrm{NH}+\mathrm{CO}$ \\
$\mathrm{R} 430$ & $\mathrm{NH}+\mathrm{NO} \Leftrightarrow \mathrm{N}_{2} \mathrm{O}+\mathrm{H}$ & $\mathrm{R} 546$ & $\mathrm{HNCO}+\mathrm{O} \Leftrightarrow \mathrm{NCO}+\mathrm{OH}$ \\
$\mathrm{R} 432$ & $\mathrm{NH}+\mathrm{NO} \Leftrightarrow \mathrm{N}_{2}+\mathrm{OH}$ & $\mathrm{R} 547$ & $\mathrm{HNCO}+\mathrm{O} \Leftrightarrow \mathrm{NH}+\mathrm{CO}$ \\
$\mathrm{R} 434$ & $\mathrm{NH}+\mathrm{NO} \mathrm{N}_{2} \Leftrightarrow \mathrm{N}_{2} \mathrm{O}+\mathrm{OH}$ & $\mathrm{R} 548$ & $\mathrm{HNCO}+\mathrm{O} \Leftrightarrow \mathrm{HNO}+\mathrm{CO}$ \\
$\mathrm{R} 435$ & $\mathrm{~N}+\mathrm{OH} \Leftrightarrow \mathrm{NO}+\mathrm{H}$ & $\mathrm{R} 571$ & $\mathrm{NCO}+\mathrm{O} \Leftrightarrow \mathrm{NO}+\mathrm{CO}$ \\
$\mathrm{R} 436$ & $\mathrm{~N}+\mathrm{O}_{2} \Leftrightarrow \mathrm{NO}+\mathrm{O}$ & $\mathrm{R} 697$ & $\mathrm{C}+\mathrm{NO} \Leftrightarrow \mathrm{CN}+\mathrm{O}$ \\
$\mathrm{R} 437$ & $\mathrm{~N}+\mathrm{NO} \Leftrightarrow \mathrm{N}_{2}+\mathrm{O}$ & $\mathrm{R} 698$ & $\mathrm{C}+\mathrm{NO} \Leftrightarrow \mathrm{CO}+\mathrm{N}$
\end{tabular}

$\mathrm{R} 438 \mathrm{NNH} \Leftrightarrow \mathrm{N}_{2}+\mathrm{H}$

${ }^{a}$ The sequence numbers (no.) of elementary reactions are derived from the reaction mechanism database. ${ }^{17}$ 
Thus, the increase in pressure results in an exponential increase in free radical concentration and promotes the establishment of a radical pool. This radical pool then triggers numerous elementary reactions, sustains the entire combustion process, involves $\mathrm{N}$ conversion, and consumes fuel to the end.

\subsection{ROP analysis of NO}

ROP analysis of the modeling calculations was performed to study the transformation of $\mathrm{N}$ and obtain an improved understanding of $\mathrm{N}$ transformation in pressurized oxy-fuel combustion. The major elementary reactions involving $\mathrm{N}$ transformation are presented in Table 3. Positive and negative ROP values indicate the rates of formation and consumption of NO, respectively.

In atmospheric oxy-fuel combustion, the six major elementary reactions involving NO production are R423, R435, R436, R571, R697, and R698, as shown in Fig. 5a. The first four elementary reactions (R423, R435, R436, and R571) were crucial in promoting NO formation. The last two elementary reactions (R697 and R698) mainly worked on NO consumption. R571 participated in the entire reaction process and displayed the highest reaction rate (with a maximum reaction rate of $1.48 \times$
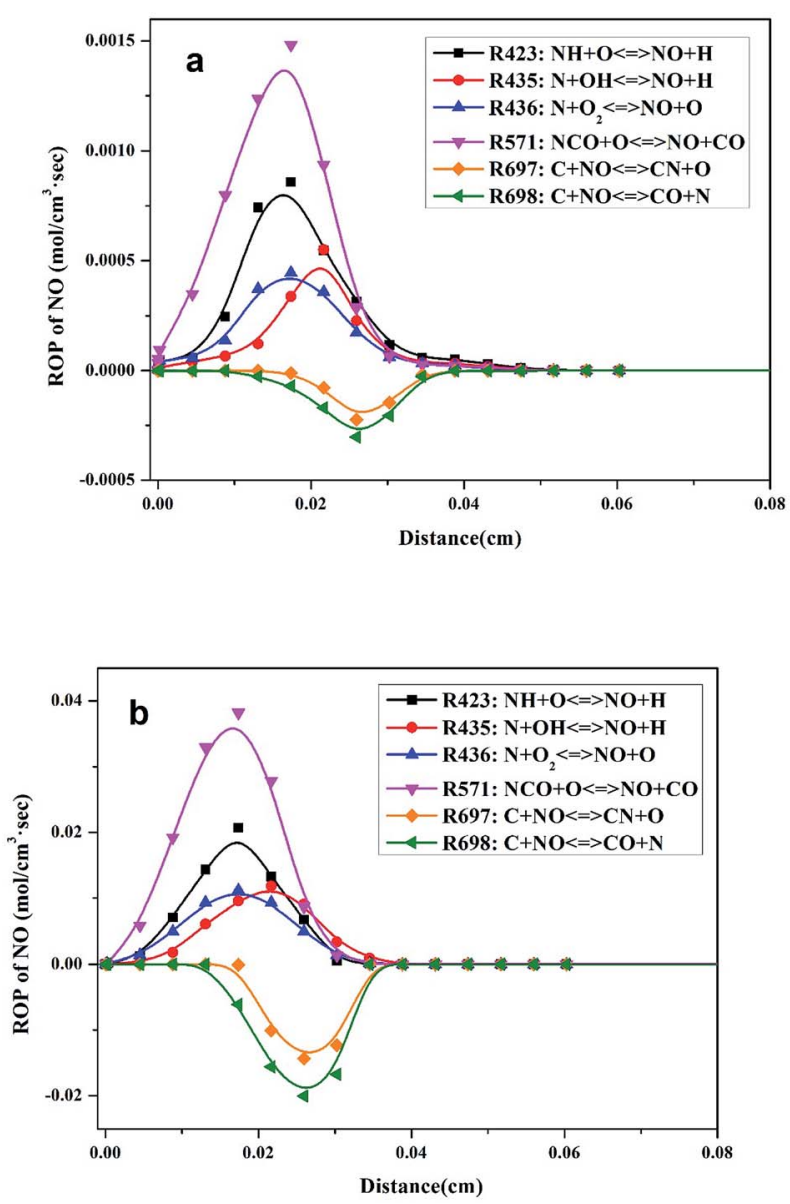

Fig. 5 Reaction rate of $\mathrm{NO}$ as a function of reactor distance in (a) atmospheric oxy-fuel combustion and (b) pressurized (1.1 MPa) oxyfuel combustion. The modeling is simulated at a temperature of $900{ }^{\circ} \mathrm{C}$ and excess air ratio of 1.0 .
$10^{-3} \mathrm{~mol} \mathrm{~cm}^{-3} \mathrm{~s}^{-1}$ ) of NO production, implying that NCO might be the prior intermediate product with regard to NO formation. R423, R435, and R436 also exhibited remarkable acceleration in $\mathrm{NO}$ formation, verifying that $\mathrm{NH}$ and $\mathrm{N}$ acted as the two other chief intermediate products. On the contrary, a fraction of generated NO was consumed mainly through R697 and R698. This result can be ascribed to the reduction atmosphere at the initial stage of combustion. The generated NO diffused and transferred to the vicinity of unburned char then triggered a typical heterogeneous reaction between gaseous NO and unburned char. After adsorption on the surface of char, the NO molecules combined with the active species on the carbon surface and were reduced into low-valence species thereafter. $^{31,32}$ However, the maximum reaction rates of $\mathrm{R} 697$ and R698 were relatively lower than those of R423, R435, R436, and R571. This result implies that considerable quantities of NO existed in the flue gas, which is in accordance with the results in Fig. 3a.

After pressurizing the combustion process, the six major elementary reactions that involved NO production and consumption were unchanged, as illustrated in Fig. 5b. Notably, the reaction rates of these six elementary reactions were improved greatly. With regard to the main NO production reaction (R571), the maximum reaction rate increased to $3.82 \times$ $10^{-2} \mathrm{~mol} \mathrm{~cm}{ }^{-3} \mathrm{~s}^{-1}$. The maximum reaction rates of the main NO consumption reactions (R697 and R698) were also significantly enhanced. Furthermore, the maximum reaction rates of R697 and R698 increased to the same magnitude order as R571, which is slightly different from the situation in atmospheric combustion. Thus, we infer that the NO content in the flue gas decreased distinctly, whereas the low-valence $\mathrm{N}$ species $\left(\mathrm{N}_{2}\right)$ increased, as verified by the results in Fig. $3 \mathrm{~b}$.

The rapid increase in reaction rate under the pressurized condition can be explained by chemical reaction rate (1), Arrhenius (2), and Clapeyron (3) equations.

$$
\begin{gathered}
r=k[\mathrm{HCN}]^{M}\left[\mathrm{O}_{2}\right]^{N}, \\
k=A \exp \left(\frac{-E_{\mathrm{a}}}{R T}\right),
\end{gathered}
$$

$$
P V=n R T,
$$

where $r$ is the chemical reaction rate in $\operatorname{mol~L}^{-1} \mathrm{~s}^{-1},[\mathrm{x}]$ is the concentration of reactant $x$ in $\mathrm{mol} \mathrm{L}^{-1}, M$ and $N$ are the orders of the reaction, $k$ is the reaction rate constant in $\mathrm{s}^{-1}, A$ is the preexponential factor in $\mathrm{s}^{-1}, E_{\mathrm{a}}$ is the activation energy in $\mathrm{J} \mathrm{mol}^{-1}, R$ is the ideal gas constant $\left(8.314 \mathrm{~J} \mathrm{~K}^{-1} \mathrm{~mol}^{-1}\right), T$ is temperature in $\mathrm{K}, P$ is pressure in $\mathrm{Pa}, V$ is the gas volume in $\mathrm{L}$, and $n$ is the molar amount in mol.

We assumed that the gaseous components in this reactor are ideal. In this modeling, the reaction rate constant $(k)$ was unchanged because the temperature $(T)$ was constant according to eqn (2). As the pressure $(P)$ increased, the molar amount $(n)$ and/or concentration $[\mathrm{x}]$ of the reactants increased because the gas volume $(V)$ was constant according to eqn (3). Thereafter, the reaction rate $(r)$ augments exponentially with the increase of 
[x] according to eqn (1). This conclusion has been proven by many studies and is in accordance with our modeling results. ${ }^{33-35}$

In summary, after pressurizing the combustion system, the promotion of NO consumption rate exceeded that of NO production rate. The decrease in emitted NO content in pressurized oxy-fuel combustion synergistically resulted from the six major elementary reactions, namely, R423, R435, R436, R571, R697, and R698.

\subsection{Key reaction paths}

The key reaction paths involving $\mathrm{N}$ transformation in oxy-fuel combustion were described in accordance with the ROP and sensitivity analyses in this modeling, as demonstrated in Fig. 6. The reaction paths were complicated processes that involved multiple elementary reactions toward multiple potential directions. Nevertheless, fuel-N (HCN) generally reacted initially with $\mathrm{H}, \mathrm{O}$, and $\mathrm{OH}$ radicals to generate $\mathrm{NCO}, \mathrm{HNCO}$, and $\mathrm{HNC}$. These three species are pivotal products to start HCN conversion, not only to $\mathrm{NO}_{x}$ but also to $\mathrm{N}_{2} \cdot{ }^{36-39}$

During the entire oxidation process from $\mathrm{HCN}$ to $\mathrm{NO}$, the $\mathrm{O}$ radical acted as the main oxidant. Initially, $\mathrm{HCN}$ was converted to NCO and HNCO through R516 and R521, followed by the oxidation of HNCO to NCO via R546. Plenty of NCO was formed and accumulated by these three reaction paths. According to Glarborg, ${ }^{36}$ the subsequent reaction of NCO largely determines the fate of $\mathrm{N}$ atoms in the NO formation process, which is in good agreement with our modeling results. As the major precursor of NO, the NCO generated from R516, R521, and R546

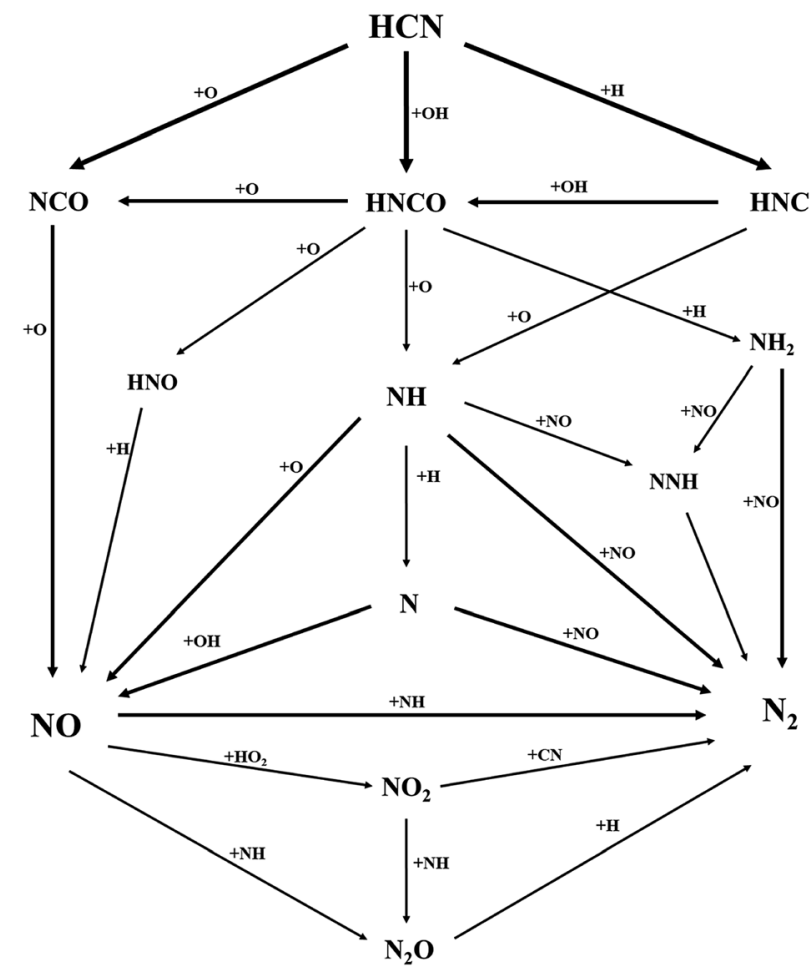

Fig. 6 Reaction paths of nitrogen transformation in pressurized oxyfuel combustion. was further oxidized by the O radical through R571. However, a small fraction of the generated HNCO from R521 was converted to $\mathrm{NH}, \mathrm{N}$, and $\mathrm{HNO}$ through R547, R422, and R548, respectively. The generated $\mathrm{NH}, \mathrm{N}$, and $\mathrm{HNO}$ were further oxidized to NO through R423, R435, and R351. In this manner, the migration and conversion of $\mathrm{N}$ atoms from $\mathrm{HCN}$ to NO was completed. Thereafter, the conversion from $\mathrm{NO}$ to $\mathrm{NO}_{2}$ and $\mathrm{N}_{2} \mathrm{O}$ was triggered through R361, R430, and R434. According to these reaction paths, the free radical pool played a crucial role throughout the entire oxidation process involving $\mathrm{NO}_{x}$ formation.

Fig. 6 also illustrates the conversion from $\mathrm{HCN}$ to $\mathrm{N}_{2}$. Initially, HCN was converted to HNCO and HNC through R521 and R514. The generated HNC was partially converted into HNCO through R527. Then, conversion from HNCO and HNC to $\mathrm{N}, \mathrm{NH}$, and $\mathrm{NH}_{2}$ was realized through $\mathrm{R} 547, \mathrm{R} 544, \mathrm{R} 526$, and R422. Notably, the subsequent reactions between $\mathrm{N} / \mathrm{NH} / \mathrm{NH}_{2}$ produced from the abovementioned reactions and the NO generated in the aforementioned paths were the key step of $\mathrm{N}_{2}$ formation in the process. ${ }^{37,38}$ As shown in Fig. 6, $\mathrm{N}, \mathrm{NH}$, and $\mathrm{NH}_{2}$ reacted with NO through R437, R432, and R417. Another intermediate product, $\mathrm{NNH}$, which participates in the $\mathrm{N}$ transformation of most oxy-fuel combustion, ${ }^{39}$ was also evident. $\mathrm{NNH}$ was produced through R442 and R418. As an unstable species, NNH dissociated automatically into $\mathrm{N}_{2}$ through $\mathrm{R} 442$ and R418. However, a small fraction of $\mathrm{NO}_{2}$ and $\mathrm{N}_{2} \mathrm{O}$ generated in the aforementioned paths was reduced into $\mathrm{N}_{2}$ through $\mathrm{R} 537$ and R391. Herein, the migration and conversion of $\mathrm{N}$ atoms from $\mathrm{HCN}$ to $\mathrm{N}_{2}$ were demonstrated.

In summary, $\mathrm{H}, \mathrm{O}$, and $\mathrm{OH}$ radicals were vital to sustaining and accelerating the entire reaction process. NCO acted as the major precursor to form NO. NO could be further converted into $\mathrm{NO}_{2}$ and $\mathrm{N}_{2} \mathrm{O}$. Furthermore, the reactions among $\mathrm{N}, \mathrm{NH}, \mathrm{NH}_{2}$, and $\mathrm{NO}$ were the key steps of $\mathrm{N}_{2}$ formation. $\mathrm{NO}_{2}$ and $\mathrm{N}_{2} \mathrm{O}$ could also be converted into $\mathrm{N}_{2}$ through particular paths. Generally, the migration and conversion of $\mathrm{N}$ atoms in oxy-fuel combustion are complicated with regard to the formation and consumption of $\mathrm{N}$ species.

\subsection{Effect of operation pressure}

Fig. 7 demonstrates the trend of $\mathrm{N}$ products as a function of operation pressure in pressurized oxy-fuel combustion. The NO molar fraction displayed a significant reduction when the operation pressure increased from 0.1 MPa to 2.1 MPa. On the contrary, the molar fraction of $\mathrm{N}_{2}$ showed an opposite trend as the pressure increased. In this modeling, oxy-fuel combustion was conducted under $\mathrm{O}_{2} / \mathrm{CO}_{2}$ atmosphere with a temperature of less than $1000{ }^{\circ} \mathrm{C}$. Thus, almost all of the NO can be considered to have been produced from fuel-N.

The increasing operation pressure exerted two effects on NO emission. First, the concentration $[\mathrm{x}]$ of reactants increased with the increase in total pressure, leading to the acceleration of the oxidation reaction rate from fuel-N to $\mathrm{NO}$, as discussed in Section 3.3. Therefore, the molar fraction of NO in the flue gas increased accordingly. Second, the partial pressure and concentration of $\mathrm{CO}_{2}$ also increased with the increase in total 


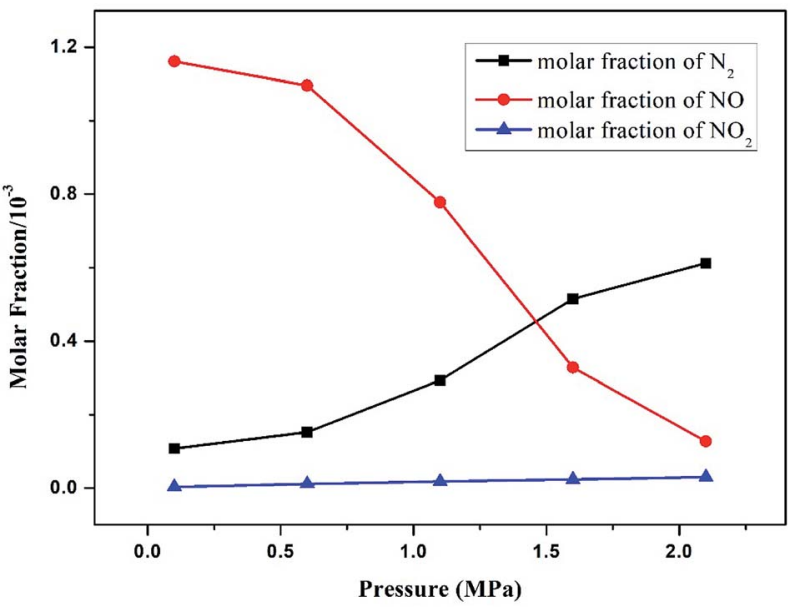

Fig. 7 Effect of operation pressure on the main nitrogen products simulated at a temperature of $900{ }^{\circ} \mathrm{C}$ and excess air ratio of 1.0.

pressure. ${ }^{40-42}$ The high $\mathrm{CO}_{2}$ partial pressure resulted in an elevated concentration of $\mathrm{CO}$ through the following reactions.

$$
\begin{gathered}
\mathrm{CO}_{2}+\mathrm{C} \rightarrow 2 \mathrm{CO} \\
2 \mathrm{CO}_{2} \rightarrow 2 \mathrm{CO}+\mathrm{O}_{2}
\end{gathered}
$$

Thereafter, the generated CO promoted the reduction of NO through the following reaction.

$$
2 \mathrm{NO}+2 \mathrm{CO} \rightarrow \mathrm{N}_{2}+2 \mathrm{CO}_{2}
$$

The high pressure inhibited the diffusion of NO from the internal to the external part of char, thereby prolonging the residence time of NO inside the char. As discussed in Section 3.3, the high NO concentration triggered a typical heterogeneous reduction with unburned char through the following reaction.

$$
2 \mathrm{NO}+2 \mathrm{C} \rightarrow \mathrm{N}_{2}+2 \mathrm{CO}
$$

According to these demonstrations, the increase in total pressure was beneficial to $\mathrm{NO}$ reduction and $\mathrm{N}_{2}$ formation. The molar fraction of $\mathrm{NO}_{2}$ also increased slightly with the increase in pressure. This condition can be ascribed to the promotion of the following reaction.

$$
2 \mathrm{NO}+\mathrm{O}_{2} \rightarrow 2 \mathrm{NO}_{2}
$$

However, this reaction was limited because the pressure and residence time were insufficient to realize complete oxidation to $\mathrm{NO}_{2} \cdot{ }^{43}$

In summary, operation pressure exerted a joint effect on NO formation and reduction. The molar fraction of NO decreased with the increase in total pressure, whereas that of $\mathrm{N}_{2}$ increased.

\subsection{Effect of temperature}

Temperature is an important factor that influences the conversion of combustion products, especially $\mathrm{N}$ oxides.

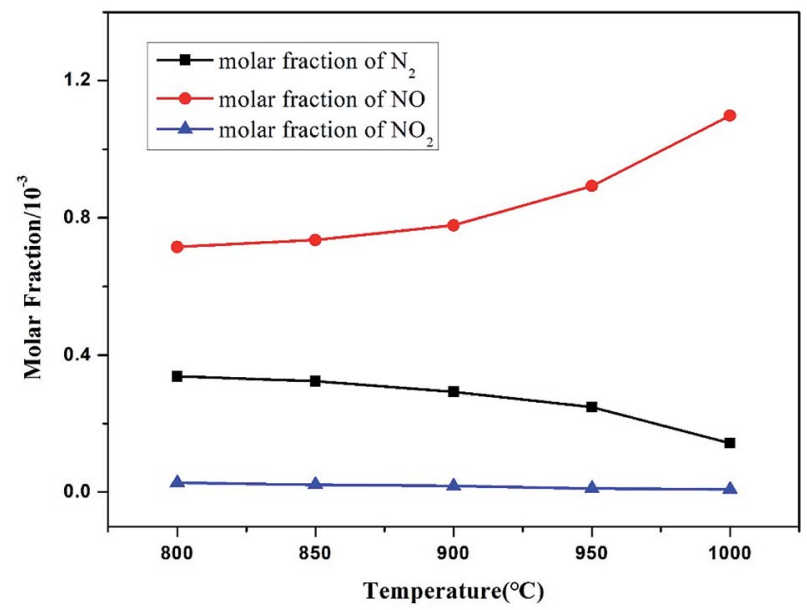

Fig. 8 Effect of temperature on the main nitrogen products simulated at an operation pressure of $1.1 \mathrm{MPa}$ and excess air ratio of 1.0.

Improving the temperature of a combustion system exerts complex effects on $\mathrm{N}$ evolution. ${ }^{44}$ The oxidation of $\mathrm{N}$ into $\mathrm{NO}$ is accelerated, and the reduction of $\mathrm{N}$ from high valence to low valence is facilitated. Thus, the NO molar fraction in flue gas is an integrated result of multiple reactions.

As shown in Fig. 8, the final molar fraction of NO emitted from the reactor increased with the increase in temperature, whereas $\mathrm{N}_{2}$ and $\mathrm{NO}_{2}$ displayed the opposite trend. Generally, not all of $\mathrm{N}$ atoms can be deeply oxidized to high-valence $\mathrm{N}$ (NO and $\mathrm{NO}_{2}$ ) at a low-temperature range due to the relatively low reaction rate and reactivity. Moreover, reductive $\mathrm{N}$ species, such as $\mathrm{HCN}, \mathrm{NH}_{3}$, and $\mathrm{HNCO}$, that are not timely oxidized certainly react with $\mathrm{NO}$ to generate a considerable amount of $\mathrm{N}_{2}$ through a similar path of the SNCR process. ${ }^{45,46}$ Therefore, the oxidation products consist of medium-valence $\mathrm{N}\left(\mathrm{N}_{2}\right)$ and high-valence $\mathrm{N}$ ( $\mathrm{NO}$ and $\mathrm{NO}_{2}$ ) at a low-temperature range.

After the temperature range moved to a high value, the reaction rate and reactivity of the oxidant were activated, and many nitrogen species were oxidized to a high valence. Meanwhile, a large amount of NO was retained because the reductive $\mathrm{N}$ species were rapidly consumed. Therefore, the molar fraction of $\mathrm{NO}$ increased with increasing temperature, whereas a reverse trend was obtained for $\mathrm{N}_{2}$ conversion, which is consistent with the results of previous studies. ${ }^{47-49}$ In a similar combustion, ${ }^{45}$ the amount of fuel- $\mathrm{N}$ converted to $\mathrm{NO}_{2}, \mathrm{~N}_{2} \mathrm{O}$, and $\mathrm{NH}_{3}$ is relatively small, with only $\mathrm{NO}$ being formed in large amounts, which is in accordance with this study. In summary, the formation of NO is thermodynamically favored as the temperature increases.

\subsection{Effect of excess air ratio}

Excess air ratio is another crucial factor that affects pulverized coal combustion and $\mathrm{N}$ conversion. The conversion ratio from fuel-N to $\mathrm{NO}$ (denoted as $\mathrm{CR}_{\mathrm{NO}}$ ) was calculated with the following equation to evaluate the conversion degree of fuel-N.

$$
\mathrm{CR}_{\mathrm{NO}}=\frac{c_{\mathrm{NO}}}{c_{\text {fuel-N }}} \times 100 \%,
$$




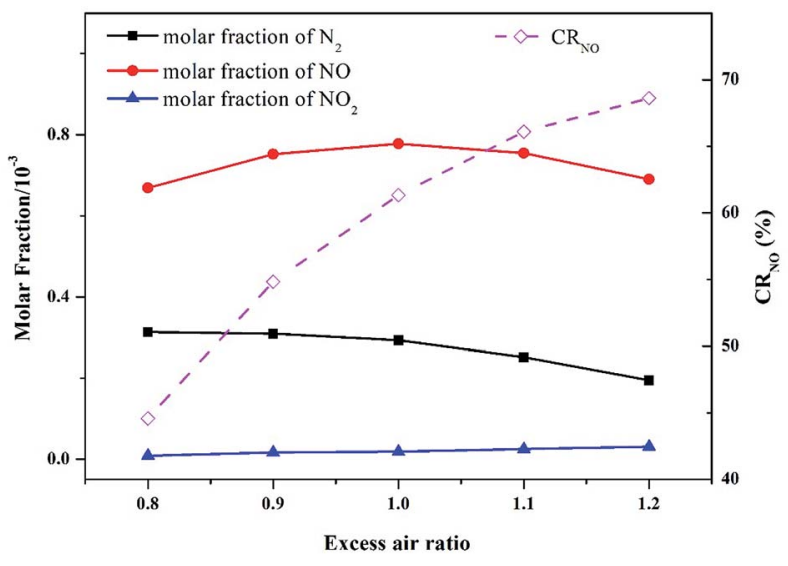

Fig. 9 Effect of excess air ratio on the main nitrogen products simulated at an operation pressure of $1.1 \mathrm{MPa}$ and temperature of $900{ }^{\circ} \mathrm{C}$.

where $\mathrm{CR}_{\mathrm{NO}}$ is the conversion ratio from fuel- $\mathrm{N}$ to $\mathrm{NO}(\%), c_{\mathrm{NO}}$ is the concentration of gaseous NO, and $c_{\text {fuel-N }}$ is the concentration of $\mathrm{N}$ in the estimated volatile composition illustrated in Table 2. The molar fractions of main $\mathrm{N}$ products and $\mathrm{CR}_{\mathrm{NO}}$ as a function of the excess air ratio in pressurized oxy-fuel combustion are presented in Fig. 9.

As shown in the figure, $\mathrm{CR}_{\mathrm{NO}}$ increased gradually with the increase in the excess air ratio. When the excess air ratio exceeded 1.0, the concentration of inlet oxygen was higher than the required molar ratio for complete combustion of $\mathrm{N}$ and $\mathrm{C}$ species. In this case, the reductive species, such as $\mathrm{HCN}, \mathrm{NH}_{3}$, and $\mathrm{HNCO}$, were rapidly consumed and adequately oxidized into high-valence $\mathrm{N}\left(\mathrm{NO}\right.$ and $\mathrm{NO}_{2}$ ). Meanwhile, the incomplete combustion carbon species, such as $\mathrm{CO}$ and unburned char, were reduced due to the high oxygen content, thus decreasing the chance of $\mathrm{CO} / \mathrm{NO}$ and char/NO reduction. In short, the reduction reactions in the combustion system were greatly suppressed, leading to the high $\mathrm{CR}_{\mathrm{NO}}$ in the excess air ratio range over 1.0.

However, the N conversion ratio to NO decreased substantially as the excess air ratio declined. A $17 \%$ decrease in $\mathrm{CR}_{\mathrm{NO}}$ was observed as the excess air ratio decreased from 1.0 to 0.8 , but the $\mathrm{N}_{2}$ molar fraction increased by $7 \%$. The formation of NO was inhibited under the low excess air ratio condition, and the generation of $\mathrm{N}_{2}$ was promoted. In other words, appropriately reducing the excess air ratio is conducive to lowering the NO emission.

\subsection{Effect of recycling ratio}

In practice, oxy-fuel combustion always involves the FGR process. As discussed in Section 3.1, the flue gas of oxy-fuel combustion mainly consists of $\mathrm{CO}_{2}$ (approximately $80 \%$, as shown in Fig. 2) and $\mathrm{H}_{2} \mathrm{O}$ (nearly $20 \%$, not shown here). Therefore, a part of the flue gas is recycled into the intake system to replace proportional inlet $\mathrm{CO}_{2}$ after simple drying and filtration. Accordingly, the cost of $\mathrm{CO}_{2}$ capture for oxy-fuel combustion is reduced, and the net power generation efficiency of the system is improved. A series of modeling with different recycling ratios ranging from 0 to 0.8 was conducted to

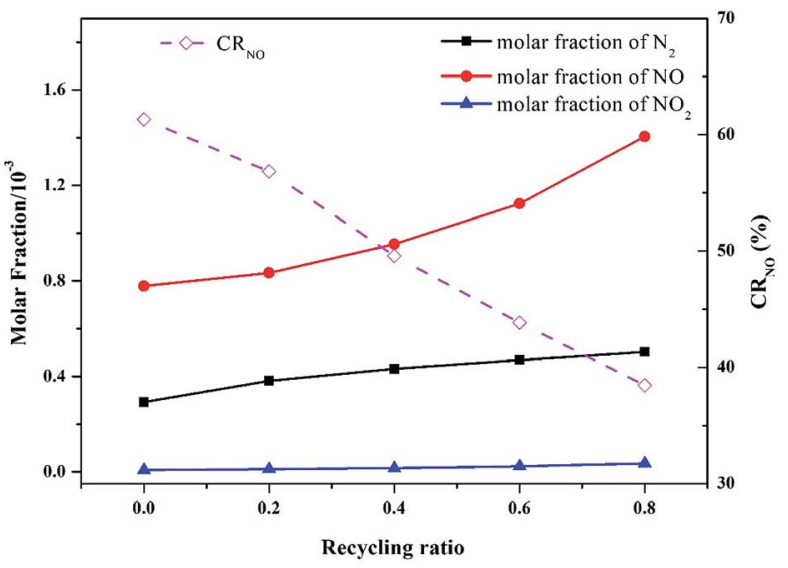

Fig. 10 Effect of recycling ratio on the main nitrogen products simulated at an operation pressure of $1.1 \mathrm{MPa}$, temperature of $900{ }^{\circ} \mathrm{C}$, and excess air ratio of 1.0

obtain insights into the actual $\mathrm{N}$ evolution process during pressurized oxy-fuel combustion.

Fig. 10 presents the effect of recycling ratio on the main $\mathrm{N}$ products. The NO molar fraction in the flue gas generally increased as the recycling ratio increased. In the experiments with FGR, a high concentration of NO was recycled along with $\mathrm{CO}_{2}$ into the inlet mixture, thereby improving the NO molar fraction in the final flue gas. Thus, the higher the recycling ratio is, the more concentrated the emitted NO is.

Additionally, the conversion ratio from fuel- $\mathrm{N}$ to $\mathrm{NO}\left(\mathrm{CR}_{\mathrm{NO}}\right)$ decreased with the increase in recycling ratio. This result can be ascribed to the reaction between reductive $\mathrm{N}$ species ( $\mathrm{HCN}$, NCO, and HNCO) and recycled NO. Large amounts of reductive $\mathrm{N}$ species were rapidly consumed by recycled $\mathrm{NO}$ as the recycling ratio increased. These $\mathrm{N}$ species are vital precursors to form NO, as discussed in Section 3.4. Thus, the oxidation paths to form NO were inhibited, leading to a continuous reduction of $\mathrm{CR}_{\mathrm{NO}}$ as the recycling ratio increased. Moreover, the reactions between reductive $\mathrm{N}$ species and recycled NO produced abundant $\mathrm{N}_{2}$, resulting in an evident increase in $\mathrm{N}_{2}$ molar fraction in the flue gas, as illustrated in Fig. 10. These results are in accordance with those reported by Yang in a similar investigation on the coal reburning process. ${ }^{50}$ The authors concluded that an increase in NO concentration in inlet gas might lead to a decrease in $\mathrm{HCN}$ and an increase in $\mathrm{N}_{2}$ in the exhausted gas. In this study, fuel-derived HCN accounted for $10 \%$ of the NO reduction in the flue gas at the initial stage of combustion. However, the detailed mechanism still needs to be explored.

Notably, the conversion ratio from fuel-N to $\mathrm{NO}\left(\mathrm{CR}_{\mathrm{NO}}\right)$ displayed an opposite trend of final NO concentration. However, no contradiction was noted. A part of the flue gas was separated to be recycled and serve as inlet $\mathrm{CO}_{2}$ after involving FGR, and the rest was emitted to the vent. The FGR process decreased the flow rate of the final emitted flue gas. With regard to combustion with FGR, although the NO concentration in the flue gas was high, the final NO emission load was lower than the nonrecycle runs. 


\section{Conclusions}

In this study, chemical kinetic modeling was applied to simulate $\mathrm{N}$ transformation in the pressurized oxy-fuel combustion process of pulverized coal. Modeling accuracy was validated by experimental data at different operation pressures, and an ROP analysis was performed to determine the key reaction paths from fuel-N to different nitrogen products. NO emission was synergistically affected by six elementary reactions, in which NCO and other intermediate species were involved. The reactions among $\mathrm{N}, \mathrm{NH}, \mathrm{NH}_{2}$, and $\mathrm{NO}$ were the key paths of $\mathrm{N}_{2}$ formation. $\mathrm{NO}$ and $\mathrm{N}_{2}$ contents decreased and increased after pressurizing the combustion system, respectively. Accordingly, the high operation pressure inhibited the diffusion of NO from the internal to the external part of char. This condition prolonged the residence time of NO inside the char, triggered a typical heterogeneous reaction between gaseous NO and unburned char, and reduced the conversion from fuel-N to NO. Moreover, modeling was performed to predict $\mathrm{NO}_{x}$ emission in pressurized oxy-fuel combustion as a function of various operating parameters, including temperature and excess air and recycling ratios. This study may provide guidance for reducing pollutant emissions and improving combustion efficiency in oxy-fuel combustion, and it can serve as a reference for industrial applications involving pulverized coal combustion.

\section{Conflicts of interest}

The authors declare no conflicts of interest.

\section{Acknowledgements}

This work was supported by the National Natural Science Foundation of China (Grant no. 51661125012).

\section{References}

1 M. B. Toftegaard, J. Brix, P. A. Jensen, P. Glarborg and A. D. Jensen, Prog. Energy Combust. Sci., 2010, 36, 581-625.

2 S. D. Kenarsari, D. Yang, G. Jiang, S. Zhang, J. Wang, A. G. Russell, Q. Wei and M. Fan, RSC Adv., 2013, 3, 2273922773.

3 Y. Lu, Y. Wang, Y. Zhao, Z. Wei, Y. Li, W. Hao and Y. Zhang, RSC Adv., 2017, 7, 51036-51045.

4 Q. Shen, Y. Zheng, C. Luo, N. Ding, C.-G. Zheng and M. Thern, RSC Adv., 2015, 5, 39785-39790.

5 M. C. Stern and T. A. Hatton, RSC Adv., 2014, 4, 5906-5914. 6 J. Sun, Z. Yi, X. Zhao, Y. Zhou and C. Gao, RSC Adv., 2017, 7, 14678-14687.

7 Z. Sun, S. Su, J. Xu, K. Xu, S. Hu, Y. Wang, L. Jiang, N. Si, Y. Zhou and S. S. A. Syed-Hassan, Energy Fuels, 2017, 31, 8392-8399.

8 L. Álvarez, J. Riaza, M. V. Gil, C. Pevida, J. J. Pis and F. Rubiera, Greenhouse Gases: Sci. Technol., 2011, 1, 180-190.

9 M. C. Stewart, R. T. Symonds, V. Manovic, A. Macchi and E. J. Anthony, Fuel, 2012, 92, 107-115.
10 H. I. Mathekga, B. Oboirien, A. Engelbrecht, B. North and K. Premlal, Energy Fuels, 2016, 30, 6756-6763.

11 L. Duan, C. Zhao, W. Zhou, C. Qu and X. Chen, Fuel Process. Technol., 2011, 92, 379-384.

12 K. Andersson, F. Normann, F. Johnsson and B. Leckner, Ind. Eng. Chem. Res., 2008, 47, 1835-1845.

13 Y. Tan, E. Croiset, M. A. Douglas and K. V. Thambimuthu, Fuel, 2006, 85, 507-512.

14 J. A. Lasek, M. Janusz, J. Zuwała, K. Głód and A. Iluk, Energy, 2013, 62, 105-112.

15 M. Lei, X. Huang, C. Wang, W. Yan and S. Wang, J. Therm. Anal. Calorim., 2016, 126, 1067-1075.

16 T. Mendiara and P. Glarborg, Energy Fuels, 2009, 23, 35653572.

17 H. Hashemi, S. Hansen, M. B. Toftegaard, K. H. Pedersen, A. D. Jensen, K. Dam-Johansen and P. Glarborg, Energy Fuels, 2011, 25, 4280-4289.

18 P. Glarborg, A. Jensen and J. E. Johnsson, Prog. Energy Combust. Sci., 2003, 29, 89-113.

19 J. Leppälahti, Fuel, 1995, 74, 1363-1368.

20 Y. Duan, L. Duan, E. J. Anthony and C. Zhao, Fuel, 2017, 189, 98-106.

21 M. Østberg, P. Glarborg, A. Jensen, J. E. Johnsson, L. S. Pedersen and K. Dam-Johansen, Symposium (International) on Combustion, 1998, 27, 3027-3035.

22 M. U. Alzueta, R. Bilbao, A. Millera, P. Glarborg, M. Østberg and K. Dam-Johansen, Energy Fuels, 1998, 12, 329-338.

23 P. Glarborg, P. G. Kristensen, K. Dam-Johansen, M. Alzueta, A. Millera and R. Bilbao, Energy Fuels, 2000, 14, 828-838.

24 E. Vilas, U. Skifter, A. D. Jensen, C. López, J. Maier and P. Glarborg, Energy Fuels, 2004, 18, 1442-1450.

25 S. Niksa and S. Cho, Energy Fuels, 1996, 10, 463-473.

26 J. C. Chen and S. Niksa, Energy Fuels, 1992, 6, 254-264.

27 A. J. Mackrory, Ph.D. thesis, Brigham Young University, 2008.

28 J. Huang and W. Bushe, Combust. Flame, 2006, 144, 74-88.

29 P. Zhang, J. Ran, C. Qin, X. Du, J. Niu and L. Yang, Energy Fuels, 2018, 32, 3900-3907.

30 M. S. Child, Molecular collision theory, Courier Corporation, 1996.

31 W. Shangguan, Y. Teraoka and S. Kagawa, Appl. Catal., B, 1997, 12, 237-247.

32 M. Higashi, S. Uchida, N. Suzuki and K. Fujii, IEEE Trans. Plasma Sci., 1992, 20, 1-12.

33 T. F. Wall, G.-s. Liu, H.-w. Wu, D. G. Roberts, K. E. Benfell, S. Gupta, J. A. Lucas and D. J. Harris, Prog. Energy Combust. Sci., 2002, 28, 405-433.

34 D. Roberts and D. Harris, Energy Fuels, 2000, 14, 483-489. 35 R.-L. Du, K. Wu, D.-A. Xu, C.-Y. Chao, L. Zhang and X.-D. Du, Fuel Process. Technol., 2016, 148, 295-301.

36 P. Glarborg and P. Marshall, Energy Fuels, 2017, 31, 21562163.

37 Y. He, X. Zheng, J. Luo, H. Zheng, C. Zou, G. Luo and C. Zheng, Energy Fuels, 2017, 31, 10093-10100.

38 H. Xiao, Z. Wang, A. Valera-Medina and P. J. Bowen, J. Therm. Sci., 2018, 27, 270-276. 
39 S. J. Klippenstein, L. B. Harding, P. Glarborg and J. A. Miller, Combust. Flame, 2011, 158, 774-789.

40 J. A. Lasek, K. Głód, M. Janusz, K. Kazalski and J. Zuwała, Energy Fuels, 2012, 26, 6492-6500.

41 K. Okazaki and T. Ando, Energy, 1997, 22, 207-215.

$42 \mathrm{Y}$. Hu, N. Kobayashi and M. Hasatani, Energy Convers. Manage., 2003, 44, 2331-2340.

43 F. Normann, K. Andersson, B. Leckner and F. Johnsson, Prog. Energy Combust. Sci., 2009, 35, 385-397.

44 Y. Hu, N. Kobayashi and M. Hasatani, Fuel, 2001, 80, 18511855.
45 F. Winter, C. Wartha and H. Hofbauer, Bioresour. Technol., 1999, 70, 39-49.

46 L. Duan, Y. Duan, C. Zhao and E. J. Anthony, Fuel, 2015, 150, 8-13.

47 F. Kapteijn, J. Rodriguez-Mirasol and J. A. Moulijn, Appl. Catal., B, 1996, 9, 25-64.

48 A. Hayhurst and A. Lawrence, Combust. Flame, 1996, 105, 341-357.

49 C. J. Tullin, S. Goel, A. Morihara, A. F. Sarofim and J. M. Beer, Energy Fuels, 1993, 7, 796-802.

50 Y. B. Yang, E. Hampartsoumian and B. M. Gibbs, Symposium (International) on Combustion, 1998, 27, 3009-3017. 